\title{
Clinical application of 3D topographic device for monitoring scoliosis progression
}

\author{
John Thometz ${ }^{*}$ XueCheng Liu, Channing Tassone, Roger Lyon \\ From 10th International Conference on Conservative Management of Spinal Deformities - SOSORT 2013 \\ Annual Meeting \\ Chicago, IL, USA. 8-11 May 2013
}

\section{Background}

Cumulative exposure to radiation from diagnostic radiographs increases patient risk of cancer development. Minimizing exposure to radiation is desired for the patient's health, so there is a need to develop alternative non-invasive tools to measure spine deformity.

\section{Purpose}

The aims of this study were to (1) determine the reproducibility of the newly developed 3-dimensional (3D) Milwaukee Topographic System (MTS) through interand intra-rater measurements and (2) calculate the correlation between the 3D angle obtained by the device and the Cobb angle measured with radiographs.

\section{Methods}

The study group consisted of twenty children with idiopathic scoliosis (IS), aged 6-18 years, with a range of Cobb angles. The MTS is composed of two wide-angle optical cameras, two electro-magnetic sensors, a light, a software package, a positioning frame, and a desktop computer. The device required four 5 -second scan sweeps (three vertical and one horizontal) for each subject. Four measurements were performed by two investigators, alternately. Reliability for the device was measured with intra-class correlation coefficient (ICC) controlling subject effect in a stratified model. Pearson correlations were calculated as well as mean values and confidence intervals for each metric.

\section{Results}

A Pearson data analysis showed excellent intra-class correlation (ICC > 0.6) between investigators for 10 metrics,

\footnotetext{
* Correspondence: JThometz@chw.org
Dept. of Orthopaedic Surgery, Children's Hospital of WI. Medical College of

* Correspondence: JThometz@chw.org
Dept. of Orthopaedic Surgery, Children's Hospital of WI. Medical College of WI, Milwaukee, WI USA
}

Submit your next manuscript to BioMed Central and take full advantage of:

- Convenient online submission

- Thorough peer review

- No space constraints or color figure charges

- Immediate publication on acceptance

- Inclusion in PubMed, CAS, Scopus and Google Scholar

- Research which is freely available for redistribution 